\title{
Nordic Seas total alkalinity data in CARINA
}

\author{
A. Olsen \\ Bjerknes Centre for Climate Research, Uni Research, Allégaten 55, 5007 Bergen, Norway \\ Department of Chemistry, University of Gothenburg, 41296, Göteborg, Sweden
}

Received: 14 August 2009 - Published in Earth Syst. Sci. Data Discuss.: 27 August 2009

Revised: 13 November 2009 - Accepted: 30 November 2009 - Published: 10 December 2009

\begin{abstract}
Water column data of inorganic carbon and carbon relevant hydrographic and hydrochemical parameters from 188 previously non-publicly available cruises in the Arctic, Atlantic, and Southern Ocean have been retrieved and merged into a new database: CARINA (CARbon IN the Atlantic). The data have been subject to rigorous quality control (QC) in order to ensure highest possible quality and consistency. The data for most of the parameters included were examined in order to quantify systematic biases in the reported values, i.e. secondary quality control. The quality control was carried out separately in each of the three CARINA regions: The Arctic Mediterranean Seas (AMS), the Atlantic (ATL), and the Southern Ocean (SO). The AMS was further split up into the Arctic Ocean and Nordic Seas during the secondary QC. The quality control of the different parameters in the different regions is described in the series of papers in this special issue of ESSD, with this contribution focusing on the Nordic Seas total alkalinity (ALK) data.

Significant biases have been corrected for in the data products, i.e. the three merged files with measured, calculated and interpolated values for each of the three CARINA regions (AMS, SO and ATL). With the adjustments the CARINA database is consistent both internally as well as with GLODAP (Key et al., 2004) and is suitable for accurate assessments of, for example, oceanic carbon inventories and uptake rates and for model validation. Out of the 35 cruises from the Nordic Seas included in CARINA, 21 had ALK data. The data from 6 of these were found to be of low quality and should not be used. Of the others, 3 were found to be biased low and were subject to adjustment. Thus the final CARINA data product contains ALK data from 15 cruises from the Nordic Seas, and these data appear consistent to $\pm 3 \mu \mathrm{mol} \mathrm{kg}{ }^{-1}$.
\end{abstract}

\section{Data coverage and parameter measured}

Repository-Reference: doi:10.3334/CDIAC/otg.CARINA.AMS.V1.2

Available at: http://cdiac.ornl.gov/ftp/oceans/CARINA/CARINA_Database/CARINA.AMS.V1.2/

Coverage: $59.60^{\circ} \mathrm{N}-82.35^{\circ} \mathrm{N}, 34.73^{\circ} \mathrm{W}-20.05^{\circ} \mathrm{E}$

Location Name: Nordic Seas

Date/Time Start: 1992-07-03

Date/Time End: 2003-10-13

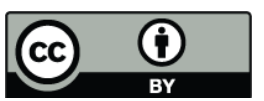

Correspondence to: A. Olsen

(are.olsen@gfi.uib.no)

Published by Copernicus Publications. 


\begin{tabular}{|c|c|c|c|c|}
\hline $\begin{array}{l}\text { Data Product } \\
\text { Parameter Name }\end{array}$ & $\begin{array}{l}\text { Data Product } \\
\text { Flag name }\end{array}$ & $\begin{array}{l}\text { Exchange File } \\
\text { Parameter Name }\end{array}$ & $\begin{array}{l}\text { Exchange File } \\
\text { Flag Name }\end{array}$ & Units \\
\hline station & & STANBR & & \\
\hline day & & DATE & & \\
\hline month & & DATE & & \\
\hline year & & DATE & & \\
\hline latitude & & LATITUDE & & decimal degrees \\
\hline $\begin{array}{l}\text { longitude } \\
\text { cruiseno }\end{array}$ & & LONGITUDE & & decimal degrees \\
\hline depth & & & & meters \\
\hline temperature & & CTDTMP & & ${ }^{\circ} \mathrm{C}$ \\
\hline salinity & sf & SALNTY & SALNTY_FLAG_W & \\
\hline ctdsal & ctdsf & CTDSAL & CTDSAL_FLAG_W & \\
\hline pressure & & CTDPRS & & decibars \\
\hline alk & alkf & ALKALI & ALKALI_FLAG_W & $\mu \mathrm{mol} \mathrm{kg}{ }^{-1}$ \\
\hline
\end{tabular}

For a complete list of all parameters available in CARINA see Key et al. (2009). Note the different names for the parameters in the Exchange files (the individual cruise files) and the merged data product.

\section{Introduction}

CARINA (CARbon In the Atlantic) is a database of carbon and carbon-relevant data from hydrographic cruises in the Arctic, Atlantic and Southern Oceans. The project started as an essentially informal, unfunded project in Delmenhorst, Germany, in 1999 during the workshop on " $\mathrm{CO}_{2}$ in the North Atlantic", with the main goal to create a uniformly formatted database of carbon relevant variables in the ocean to be used for accurate assessments of oceanic carbon inventories and uptake rates. The collection of data and the quality control (QC) of the data have been a main focus of the CARINA project. Both primary and secondary QC of the data has been performed.

The CARINA database consists of two parts: the first part is the set of the individual cruise files where all the data reported by the measurement teams are stored. Quality flags are accompanying the data, in many cases those are the flags originally reported, in others they were assigned by R. M. Key, Princeton University (Key et al., 2009). These files are in WHP (WOCE Hydrographic Program) exchange format where the first lines consist of the condensed metadata (including information on methods used for ALK determination). There are essentially no calculated or interpolated values in the individual cruise files, with the exceptions of pressure calculated from depth and some bottle salinities that were taken from ctdsal. No adjustments have been applied to any of these values with the exception that all $\mathrm{pH}$ measurements were converted to the seawater $\mathrm{pH}$ scale at $25^{\circ} \mathrm{C}$, as described by Velo et al. (2009a).

The second part of CARINA consists of three merged, quality controlled and adjusted data files; one each for the Atlantic Ocean (ATL), Arctic Mediterranean Seas (AMS) and Southern Ocean (SO) regions. These files contain all the CARINA data and also include: 1) interpolated values for nutrients, oxygen and salinity if those data were missing and the interpolation could be made according to certain criteria, as described in Key et al. (2009); 2) calculated carbon parameters; e.g. if total dissolved inorganic carbon $\left(\mathrm{TCO}_{2}\right)$ and total alkalinity (ALK) were measured, $\mathrm{pH}$ was calculated; and 3) instances where bottle salinity was missing or bad and were replaced with CTD salinity. Calculated or interpolated values have been given the quality flag " 0 ". In many cases there are additional parameters in the individual cruise files, which have not been subject to secondary QC, such as $\Delta^{14} \mathrm{C}$, $\delta^{13} \mathrm{C}$ and $\mathrm{SF}_{6}$. Many of these are included in the merged data files as well.

This report provides an overview of the ALK data from the Nordic Seas data in CARINA and describes the secondary QC of these data. The total alkalinity in sea water is defined as "...the number of moles of hydrogen ions equivalent to the excess of proton acceptors (bases formed from weak acids with a dissociation constant $K \leq 10^{-4.5}$, at $25^{\circ} \mathrm{C}$ and zero ionic strength) over proton donors (acids with $K>10^{-4.5}$ ) in one kilogram of sample." (Dickson, 1981). It is one of the four parameters that describe the inorganic carbon chemistry of seawater, the others being total dissolved inorganic carbon, the $\mathrm{CO}_{2}$ fugacity, and $\mathrm{pH}$. The Nordic Seas ALK data are part of the Arctic Mediterranean Seas subset of CARINA (CARINA-AMS). This subset includes data from the Nordic Seas and the Arctic Ocean. Not one of the cruises of CARINA covered both the Arctic Ocean and the Nordic Seas to the extent that it could be included in the secondary quality control in both regions. In addition, the differences in data density in the two regions enforced the use of different QC methods for the data collected in them. The data from these regions were therefore analysed separately. The ALK data from the Arctic Ocean are described by Jütterström et al. (2009), and the other Nordic Seas data are described in Jeansson et al. (2009), Falck and Olsen (2009), Olafsson and Olsen (2009), Olsen et al. (2009), and Olsen (2009). A more comprehensive description of the complete CARINA database can be found in Key et al. (2009), as well as in the other, more specialised, papers in this special issue, which 


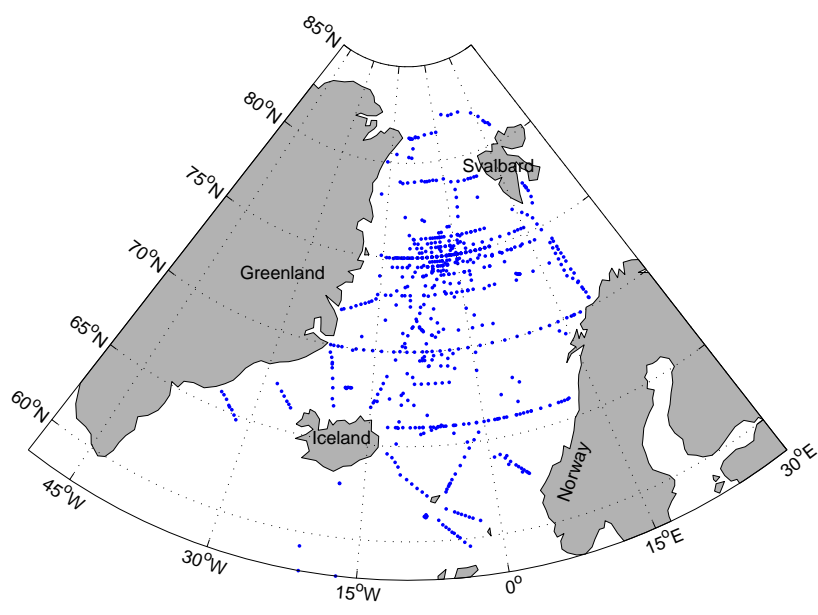

Figure 1. The Nordic Seas with ALK sampling positions, includes only data retained through analyses described here.

includes the paper describing the ALK data from the Atlantic Ocean region of CARINA (Velo et al., 2009b), and the papers providing the overview of the CARINA data in the ATL (Tanhua et al., 2009a) and SO (Hoppema et al., 2009; Lo Monaco et al., 2009; Sabine et al., 2009) regions.

\section{Data provenance}

The Nordic Seas was loosely defined as the region closed by the Fram Strait to the north, Greenland to the west, the Greenland-Scotland Ridge to the south, and Norway, the Barents Sea Opening, and Svalbard to the east (Fig. 1). Out of the 188 CARINA cruises, 62 are included in the CARINAAMS, and 35 of these are considered as Nordic Seas cruises. Five of these are in common with the Atlantic Ocean subset of CARINA (Tanhua et al., 2009a), in order to ensure consistency between the regions. Out of the 35 cruises included in the Nordic Seas CARINA, 21 had ALK data, which was generally measured on all Nordic Seas cruises with measurements of dissolved inorganic carbon $\left(\mathrm{TCO}_{2}\right)$. The only exceptions are the Iceland Sea time series, the 1993 Northeastwater Polynya cruise (32L919930818 (79), number in parenthesis is CARINA cruise number), and the 1992 and 1994 Nordic WOCE cruises: 58JH19920712 (130) and 58JH19940723 (135). Therefore the reader is referred to the Nordic Seas CARINA $\mathrm{TCO}_{2}$ paper (Olsen, 2009) for background information on the ALK data.

Table 1 provides an overview of the data that were included in the secondary QC described in this paper, and station positions are shown in Fig. 1. The Nordic Seas CARINA ALK data included in the secondary quality (QC) control span 21 years, with the earliest cruise being the 1982 Hudson (18HU19820228 (36)), and the latest the 2003 G. O. Sars cruise (58GS20030922 (128)). All of the values were determined by potentiometric titration using either a closed (Dick- son et al., 2007) or open (Haraldson et al., 1997) cell system, as further specified in Table 1. Certified Reference Material (CRM) were analysed at many cruises and used to correct the ALK data for offsets. However, as certified values for alkalinity did not become available until well into the ' 90 s some of the earlier measurements had not been offset corrected by the principal investigator. Access to the uncorrected ALK values enabled offset correction to be carried out for two of these cruises as noted in Table 1. Details on this correction are provided in the metadata files for these cruises.

\section{Quality control}

The secondary QC included an assessment of the precision of the data from each individual cruise as well as a consistency analysis. The consistency analysis was carried out using the crossover and inversion approach (Gouretski and Jancke, 2001; Johnson et al., 2001; Tanhua et al., 2009b), customised as described by Olsen et al. (2009), and through evaluating the linear relationship between salinity and ALK at the different cruises.

\subsection{Individual cruise assessments}

The metadata contained little or no information on the precision of the ALK data obtained at the different cruises, and replicate samples, which would enable determination of this, were virtually non-existent. However, distribution of chemical properties in the deep Nordic Seas is fairly homogenous (Blindheim and Østerhus, 2005; Fig. 2). Therefore, to obtain an impression of the precision of each cruise the standard deviation of samples from deeper than 1900 dbar between $65^{\circ}$ and $80^{\circ} \mathrm{N}$ and $10^{\circ} \mathrm{W}$ to $10^{\circ} \mathrm{E}$ was determined. For comparison, the data from the three cruises with all values flagged 3 prior to the secondary QC were also included in this analysis (58AA19940203 (116), 58JH19950427 (137), and 58JH19951108 (138)). These numbers are presented in Table 2. They must be interpreted with two effects in mind (1) natural spatial variability and (2) precision of measurements. As regards the first effect, consider the 316N20020530 (67) cruise, which has the largest areal coverage of all cruises with data from almost the whole region included in this exercise (Fig. 2). The standard deviation of the deep ALK data obtained on this cruise is $4.80 \mu \mathrm{mol} \mathrm{kg}{ }^{-1}$. Since all of the other cruises had smaller areal coverage their standard deviation should be the smaller. This is not always the case, many cruises show larger spread indicating poorer precision. In particular 58JH19940203 (116) with a standard deviation of $26 \mu \mathrm{mol} \mathrm{kg}{ }^{-1}$, 58JH19950427 (137) with a standard deviation of $20.3 \mu \mathrm{mol} \mathrm{kg}{ }^{-1}$, and $58 \mathrm{JH} 19951108$ (138) with $38.5 \mu \mathrm{mol} \mathrm{kg}{ }^{-1}$, all of these data had been flagged 3 during the primary QC. Other than these, the two cruises 58JH19930730 (132) and 58AA19950217 (119) had somewhat higher standard deviation than the others. The former of these had only 11 samples from deeper than 1900 dbar and 
Table 1. Nordic Seas cruises with ALK data and recommendations from the secondary quality control.

\begin{tabular}{|c|c|c|c|c|c|c|}
\hline No. ${ }^{a}$ & EXPOCODE & Country/Institute & P.I. & cell & $\mathrm{CRM}^{\mathrm{b}}$ & recommendation $^{c}$ \\
\hline 10 & 06MT19920701 ${ }^{\mathrm{d}}$ & Germany/IBM Hamburg & K. Pegler & not known & no & OK \\
\hline 36 & 18HU19820228 & Canada/BiO & E. P. Jones & closed & no & Flag 3 \\
\hline 67 & 316 N20020530 & Norway/UGOT & R. G. J. Bellerby & open & yes & $\mathrm{OK}$ \\
\hline 78 & 32L919920715 & US/Brookhaven & D. W. R. Wallace & closed & no & $\mathrm{NC}$ \\
\hline 116 & 58AA19940203 & Norway/UoB & I. Skjelvan & closed & no & Flag $3^{\mathrm{e}}$ \\
\hline 117 & 58AA19940224 & Sweden/UGOT & L. G. Anderson & open & no ${ }^{\mathrm{i}}$ & $+15.5 \mu \mathrm{mol} \mathrm{kg}{ }^{-1}$ \\
\hline 118 & 58AA19940826 & Norway/UoB & T. Johannessen & closed & no & $\mathrm{OK}$ \\
\hline 119 & 58AA19950217 & Sweden/UGOT & L. G. Anderson & open & no ${ }^{\mathrm{i}}$ & Flag 3 \\
\hline 120 & 58AA19961121 & Norway/UoB & T. Johannessen & open & yes $^{f}$ & $\mathrm{OK}$ \\
\hline 121 & 58AA19970225 & Norway/UoB & T. Johannessen & open & yes $^{\mathrm{f}}$ & $\mathrm{OK}$ \\
\hline 122 & 58AA19980308 & Norway/UoB & A. Olsen, A. Omar & open & yes & $\mathrm{OK}$ \\
\hline 125 & 58AA20010527 & Norway/UoB & A. Olsen, A. Omar & open & yes & $\mathrm{OK}$ \\
\hline 128 & 58GS20030922 & Norway/UoB & A. Olsen, T. Johannessen & open & yes & $\mathrm{OK}$ \\
\hline 132 & 58JH19930730 & Norway/UoB & T. Johannessen & closed & no & Flag 3 \\
\hline 134 & 58JH19940525 g & Norway/UoB & T. Johannsessen & closed & no & $+11.6 \mu \mathrm{mol} \mathrm{kg}{ }^{-1}$ \\
\hline 137 & 58JH19950427 & Norway/UoB & T. Johannessen & closed & no & Flag $3^{\text {h }}$ \\
\hline 138 & 58JH19951108 & Norway/UoB & T. Johannessen & closed & no & Flag $3^{\mathrm{e}}$ \\
\hline 141 & 58JH19970414 & Sweden/UGOT & L. G. Anderson & open & yes & $\mathrm{OK}$ \\
\hline 142 & 58JH19980801 & Sweden/UGOT & L. G. Anderson & open & yes & $\mathrm{OK}$ \\
\hline 176 & 74JC19960720 & Norway/UoB & T. Johannessen & open & no ${ }^{\mathrm{i}}$ & $+15.5 \mu \mathrm{mol} \mathrm{kg}{ }^{-1}$ \\
\hline 179 & 77DN20020420 & Sweden/UGOT & L. G. Anderson & open & yes & $\mathrm{OK}$ \\
\hline
\end{tabular}

${ }^{\text {a }}$ CARINA cruise number, is cruise identifier in merged datafile.

${ }^{\mathrm{b}}$ Indicates whether Certified Reference Material provided by A. G. Dickson was used to correct the data from the cruise or not.

${ }^{\mathrm{c}}$ Recommendations from the secondary QC. Flag $3=$ data are questionable and are not included in the final data product; $\mathrm{OK}=$ the data can

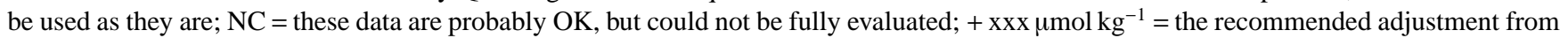
the secondary QC, this has been applied in the merged data product.

d This was the 5th and 6th leg of the 1992 Meteor cruise, only leg 5 samples were used in the analyses described in this paper.

${ }^{\mathrm{e}}$ Flagged 3 by R. M. Key during the primary QC process (Key et al., 2009).

${ }^{\mathrm{f}}$ The original data had not been corrected for CRM offset, this was done by the author as part of CARINA.

$\mathrm{g}$ The data file also contained samples that had been analysed ashore, these were flagged 3 by PI.

${ }^{\mathrm{h}}$ Flagged 3 by PI during the CARINA process.

${ }^{\mathrm{i}}$ CRMs were measured, but have not been used to correct the data, see Sect. 4.4.

these appeared reasonable. However, samples obtained in the 1000-2000 dbar depth range spanned 2270-2320 $\mu \mathrm{mol} \mathrm{kg} \mathrm{kg}^{-1}$, which is unacceptable compared to the other cruises (see Fig. 2). Additionally the $\mathrm{TCO}_{2}$ data from this cruise were of too poor quality to be included in the synthesis and given the questionable precision the ALK data were left out as well. The data from 58AA19950217 (119) have almost twice the standard deviation of 316N20020530 (67), despite covering a much smaller region, in particular there were some unrealistically low values to the east, and a simple visual inspection indicated that the data were in general $10-20 \mu \mathrm{mol} \mathrm{kg}^{-1}$ too low. Given the questionable accuracy and precision, these data were excluded from further analyses.

\subsection{Consistency analyses}

Two independent consistency analyses were carried out: (1) crossover and inversion and (2) evaluation of ALKsalinity relationships. Cruiseno 78, 32L919920715 was not included in these analyses as it was carried out in a very special region, the Northeast Water Polynya (Yager et al., 1995). This cruise has been labelled not considered (NC) in Table 1.

\subsubsection{Crossover and inversion}

The consistency of the Nordic Seas ALK data was evaluated through a crossover and inversion analysis (Gouretski and Jancke, 2001; Johnson et al., 2001). This analysis was carried out using a very early version of the cnaX scripts (Tanhua et al., 2009b) with a high degree of user supervision. First all station pairs, from the two cruises to be analysed, within $300 \mathrm{~km}$ from each other were defined as crossover points. Thus two cruises may have several crossover points. Then, the crossovers of the cruisepair were partitioned into circular clusters using a k-means routine (Seber, 1984) and the cluster with the largest amount of stations in the most homogenous region was selected for further analysis. If the $\mathrm{k}$-means routine failed to produce a satisfactory cluster, then 


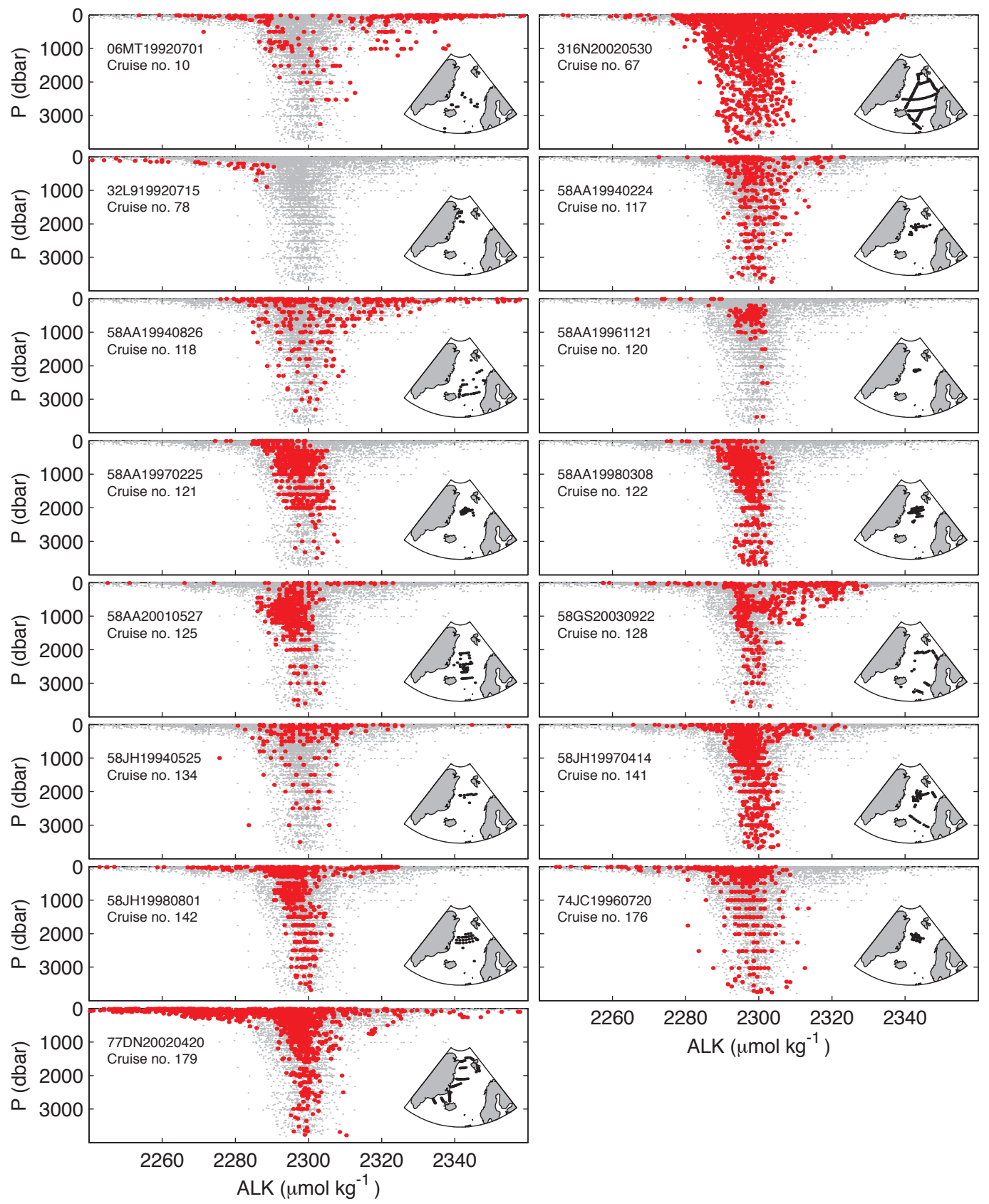

Figure 2. Station positions and ALK data of Nordic Seas CARINA cruises after secondary QC. All data shown in grey and specific cruise in red.

the centre and radius of the cluster was manually defined. As most campaigns in the Nordic Seas have been focusing on repeat occupations of the Greenland Sea, the clusters normally covered this region and had a radius of between 150 and $250 \mathrm{~km}$. After the clustering, each station in the cluster was interpolated onto $50 \mathrm{~m}$ depth intervals using a piecewise cubic Hermite interpolation, and the average profile of each of the two cruises was determined along with its standard deviation. Using these, the weighted mean offset between the two cruises and its uncertainty (the weighted mean off- set standard deviation) was computed following Johnson et al. (2001), using deep data ( $>1900 \mathrm{dbar}$ for the Nordic Seas (Olsen et al., 2009)). These were used as input for the inversion analysis, which determined the corrections required to maximise the consistency among the cruises. The inversion followed the Weighted Least Squares (WLSQ) model of Johnson et al. (2001), where the offsets are weighted by their uncertainty. In this model crossover offsets with large uncertainty are less influential than crossover offsets with smaller uncertainty. 
Table 2. Standard deviation of samples from $65-80^{\circ} \mathrm{N}, 10^{\circ} \mathrm{W}-$ $10^{\circ} \mathrm{E}$ and $p>1900 \mathrm{dbar}$.

\begin{tabular}{lll}
\hline No & EXPOCODE & std. dev. \\
\hline 10 & 06MT19920701 & 4.46 \\
36 & 18HU19820228 & 5.60 \\
67 & 316N20020530 & 4.80 \\
78 & 32L919920715 & NA $^{\mathrm{a}}$ \\
116 & 58AA19940203 & $26.0^{\mathrm{b}}$ \\
117 & 58AA19940224 & 3.50 \\
118 & 58JH19940826 & 5.31 \\
119 & 58AA19950217 & 8.14 \\
120 & 58AA19961121 & 1.04 \\
121 & 58AA19970225 & 2.37 \\
122 & 58A19980308 & 2.27 \\
125 & 58AA20010527 & 2.80 \\
128 & 58GS20020922_noEddy & 1.97 \\
132 & 58JH19930730 & 7.70 \\
134 & 58JH19940525 & 3.30 \\
137 & 58JH19950427 & $20.3^{\mathrm{b}}$ \\
138 & 58JH19951108 & $38.5^{\mathrm{b}}$ \\
141 & 58JH19970414 & 4.51 \\
142 & 58JH19980801 & 2.18 \\
176 & 74JC19960720 & 4.68 \\
179 & 77DN20020420 & 1.99 \\
\hline
\end{tabular}

${ }^{\text {a }}$ Cruise had no samples from deeper than 1900 dbar.

${ }^{\mathrm{b}}$ All ALK data were flagged 3, but were included here to illustrate the spread. Otherwise the standard deviations were determined using only data flagged 2 .

c 58GS20030922 (128) had several stations in a submesoscale coherent eddy (Kasajima et al., 2006), the "_noEddy" signifies that these data were removed prior to this analysis.

The results of this semi automated approach was virtually indistinguishable from the results derived using a more recent version of the cnaX scripts where the clustering was fully automated, and where up to 6 clusters with a maximum radius of $175 \mathrm{~km}$ was allowed for each cruise pair, described by Olsen et al. (2009).

The maps of the crossovers and clusters as well as the crossover offsets determined during this analysis are available at the CARINA website (http://cdiac.ornl.gov/ oceans/CARINA/Carina_inv.html). Here I only present the corrections suggested by the WLSQ inversion of the crossover offsets, in Fig. 3. No results were obtained for the 3 cruises 06MT19920701 (10), 58AA19940826 (118) and 58AA19961121 (120), but otherwise are there significant inconsistencies in the data. The ALK data from 18HU19820228 (36) appear $\sim 12 \mu \mathrm{mol} \mathrm{kg}^{-1}$ too high, i.e. they should be adjusted down to increase consistency. The ALK data from the three cruises 58AA19940224 (117), 58JH19940525 (134), and 74JC19960720 (176) appear between 8 and $12 \mu \mathrm{mol} \mathrm{kg}{ }^{-1}$ too low. Finally, the 58AA19970225 (121) ALK data appear approximately

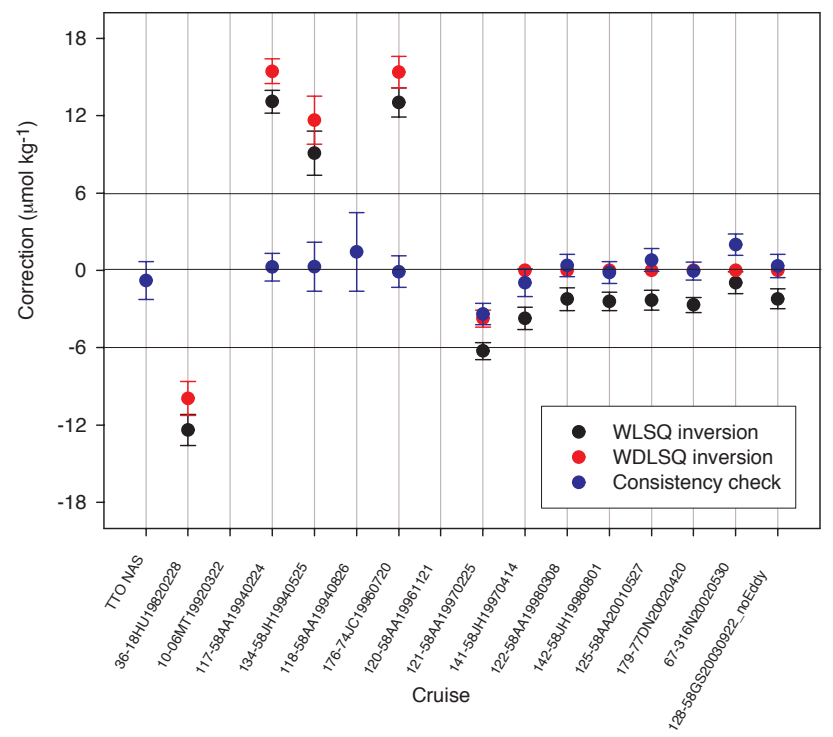

Figure 3. Corrections from the WLSQ and WDLSQ inversion of manual crossover offsets, as well as corrections determined through a cnaX analysis of the data with recommendations implemented. The corrections reflect measurement bias and natural variations, the latter is why the data with recommendations implemented also vary. 58GS20030922 (128) had several stations in a submesoscale coherent eddy (Kasajima et al., 2006), the "_noEddy" signifies that these data were removed prior to this analysis. Note that the cruises have been sorted by time in this figure. The crossover results that were used in the inversions to prepare this figure can be accessed at the CARINA website (http://cdiac.ornl.gov/oceans/ CARINA/Carina_inv.html).

$6 \mu \mathrm{mol} \mathrm{kg}{ }^{-1}$ high, which is at the CARINA wide threshold for applying ALK corrections (Tanhua et al., 2009b). The rest of the cruises appear a few $\mu \mathrm{mol} \mathrm{\textrm {kg } ^ { - 1 }}$ low, but this is in fact a consequence of the practise that the inversion objectively determines the corrections required to maximize the consistency of the cruises, i.e. no a priori assumption on what is the "correct" deep sea ALK value was invoked. Therefore the inversion has underestimated the correction needed for low cruises, and compensated by suggesting a negative correction for cruises that in reality are accurate. One may say that it misses the target. This was dealt with by providing the inversion with information on what is the correct deep Nordic Seas ALK values through a weighted damped least squares (WDLSQ) inversion which takes into account a priori assumptions on the expected magnitude of adjustments among cruises - the model error (Johnson et al., 2001). Given the results from the WLSQ inversion as well as information on CRM usage (Table 1) it is reasonable to assume that the cruises carried out after 1996 are more accurate than the cruises carried out before. A model error of zero was assigned to these, while the others were assigned a model error of $20 \mu \mathrm{mol} \mathrm{kg}^{-1}$. The suggested corrections from this inversion are shown in red in Fig. 3. The post 1996 cruises are 
accurate, as enforced in the inversion. The suggested correction for $18 \mathrm{HU} 19820228$ (36) is $-9.95 \mu \mathrm{mol} \mathrm{kg}{ }^{-1}$, which is more than $2 \mu \mathrm{mol} \mathrm{kg}{ }^{-1}$ less than the correction determined by the WLSQ inversion. The corrections for 58AA19940224 (117), 58JH19940525 (134) and 74JC19960720 (176) have all increased relative to the WLSQ inversion and are 15.45, 11.65 , and $15.38 \mu \mathrm{mol} \mathrm{kg}^{-1}$ respectively. 58AA19970225

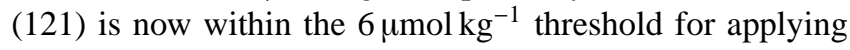
the corrections.

\subsubsection{Linear regression analysis}

To further evaluate the consistency of the data, a linear regression analysis was carried out. The ALK data obtained at $316 \mathrm{~N} 20020530$ (67) were used as a reference as this had the most extensive coverage and defined the linear regression line:

$\mathrm{ALK}=62.8 \cdot S+106.62, \quad r^{2}=0.63$

Only data obtained deeper than $50 \mathrm{~m}$ and with salinities larger than 34.5 were used. The latter cutoff was applied to avoid the influence of polar waters, which have relatively high alkalinities due to influence of Arctic river runoff (Anderson et al., 2004). Using 316N20020520 (67) as a reference was motivated by the large areal coverage, however one caveat applies: these data seemed $\sim 1-2 \mu \mathrm{mol} \mathrm{kg}{ }^{-1}$ lower than the other data from this period (Fig. 3, WLSQ inversion) and results must be interpreted with this in mind.

Table 3 gives the mean difference between measured and estimated ALK from the different cruises. Positive numbers means that the ALK data from the specific cruise are on average higher than those determined through Eq. (1). First of all, this analysis gave results for the three cruises that were not evaluated through the crossover and inversion analyses, 06MT19920701 (10), 58AA19940826 (118), and 58AA19961121 (120). None of these appear significantly offset with mean biases of $-1.43,1.63$, and $2.43 \mu \mathrm{mol} \mathrm{kg} \mathrm{kg}^{-1}$ relative to the regression line. Otherwise the mean biases confirm by and large the results of the crossover and inversion analysis. The ALK data from 18HU19820228 (36) are too high and 58AA19940224 (117), 58JH19940525 (134), and 74JC19960720 (176) are too low. Other than that, the ALK data are in general slightly higher than the ALK data from 316N20020530 (67), as expected.

\section{Recommendations}

Given the results of the crossover and inversion, and linear regression analyses the following cruises should be considered for adjustments: 18HU19820228 (36), 58AA19940224 (117), 58JH19940525 (134), and 74JC19960720 (176).
Table 3. Mean bias of ALK data when compared to values calculated from Eq. (1), measured - estimated.

\begin{tabular}{|c|c|c|c|}
\hline No & EXPOCODE & $\operatorname{Bias}\left(\mu \mathrm{mol} \mathrm{kg}{ }^{-1}\right)$ & $\mathrm{rms}$ \\
\hline 10 & 06MT19920701 & -1.43 & 6.31 \\
\hline 36 & 18HU19820228 & 10.3 & 12.1 \\
\hline 67 & 316 N20020530 & 0 (reference) & 6.5 \\
\hline 78 & 32L919920715 & $\mathrm{NC}$ & $\mathrm{NC}$ \\
\hline 116 & 58AA19940203 & $\mathrm{NC}$ & $\mathrm{NC}$ \\
\hline 117 & 58AA19940224 & -12.2 & 12.9 \\
\hline 118 & 58JH19940826 & 1.63 & 8.61 \\
\hline 119 & 58AA19950217 & $\mathrm{NC}$ & $\mathrm{NC}$ \\
\hline 120 & 58AA19961121 & 2.43 & 3.32 \\
\hline 121 & 58AA19970225 & 1.38 & 3.86 \\
\hline 122 & 58A19980308 & 0.660 & 2.43 \\
\hline 125 & 58AA20010527 & -1.41 & 3.80 \\
\hline 128 & 58GS20020922_noEddy & 1 & 4.23 \\
\hline 132 & 58JH19930730 b & $\mathrm{NC}$ & $\mathrm{NC}$ \\
\hline 134 & 58JH19940525 & -8.85 & 11.3 \\
\hline 137 & 58JH19950427 & $\mathrm{NC}$ & $\mathrm{NC}$ \\
\hline 138 & 58JH19951108 & $\mathrm{NC}$ & $\mathrm{NC}$ \\
\hline 141 & 58JH19970414 & 1.70 & 3.09 \\
\hline 142 & 58JH19980801 & 0.960 & 3.30 \\
\hline 176 & 74JC19960720 & -14.9 & 15.6 \\
\hline 179 & 77DN20020420 & 3.61 & 5.80 \\
\hline
\end{tabular}

${ }^{a}$ Not considered as the data were obtained in a very special region, the North Water Polynya (Yager et al., 1995).

${ }^{b}$ Not considered as the data appeared of insufficient precision to be included in the CARINA synthesis product (Sect. 3.1).

c 58GS20030922 (128) had several stations in a submesoscale coherent eddy (Kasajima et al., 2006), the “_noEddy" signifies that these data were removed prior to this analysis.

\section{$4.1 \quad 18 H U 19820228(36)$}

A suggested correction of $-9.95 \mu \mathrm{mol} \mathrm{kg}{ }^{-1}$ was determined through the WDLSQ inversion of the crossover offsets. A positive bias was determined through the regression analysis as well, but its magnitude can not be directly compared to the inversion result as it was determined through comparison with samples obtained deeper than $50 \mathrm{dbar}$ at one specific cruise, rather than through comparison with deep water values from all cruises. Therefore another regression was carried out where the regression line was determined using deep (>1900 dbar) data from all cruises not subject to adjustment considerations. This gave a mean bias of the 18HU19820228 (36) ALK data of $9.62 \mu \mathrm{mol} \mathrm{kg}{ }^{-1}$, essentially confirming the WDLSQ inversion result.

The offset of these data, however, does not seem to have been constant throughout the cruise. Figure 4 shows residual of ALK from Eq. (1), as a function of station number. The residuals vary and in particular, whereas the data prior to station 96 are clearly too high, the ones obtained after appear almost unbiased. This change could not be related to any of the other variables, except for $\mathrm{TCO}_{2}$, which exhibited a 


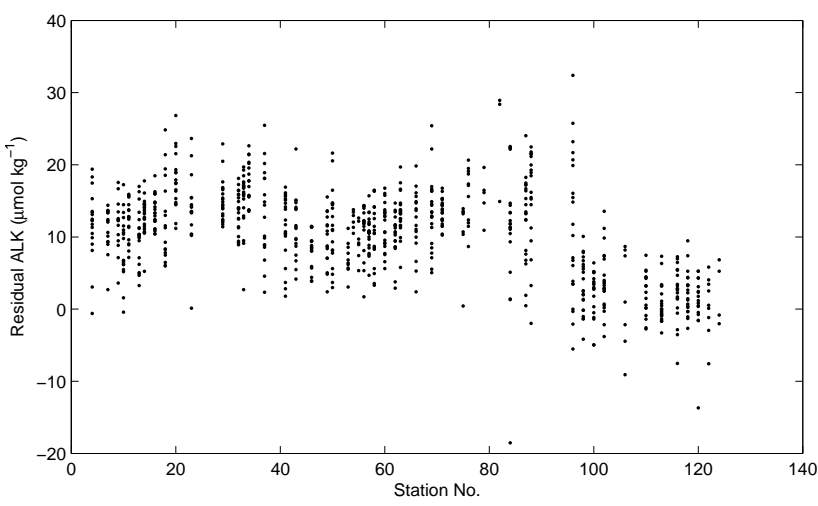

Figure 4. Difference between measured and calculated (from Eq. 1) 18HU19820228 (36) ALK values vs. station number (measured estimated).

similar change of bias (Olsen, 2009). It seems quite evident that this is caused by issues with the potentiometric titrations at the cruise. The ALK data from this cruise are therefore recommended flagged questionable and not included in the CARINA synthesis product.

\subsection{AA19940224 (117)}

The WDLSQ inversion of the crossover offsets suggested that an upward adjustment of $15.45 \mu \mathrm{mol} \mathrm{kg}{ }^{-1}$ was required to bring these data into consistency with the others. The comparison with the 316N20020530 (67) ALK data through the linear regression analysis (Sect. 3.2.2) indicated an offset of $-12.18 \mu \mathrm{mol} \mathrm{kg}^{-1}$, but as mentioned in Sect. 3.2.2 these numbers are not expected to be similar. Thus, similarly to the analysis of $18 \mathrm{HU} 19820228$ (36), the data were compared to the regression line determined using deep data from cruises not subject to adjustment considerations. This gave a mean residual of $-15.24 \mu \mathrm{mol} \mathrm{kg}^{-1}$, almost the same as the correction suggested by the WDLSQ inversion. The offset appeared constant throughout (not shown) the cruise and therefore an upward adjustment of $15.5 \mu \mathrm{mol} \mathrm{kg}^{-1}$ is recommended for these data. After the secondary QC had been completed a data file which included the results of the analyses of CRM was obtained (L. Anderson and M. Chierici, personal communication). These indicated a mean offset of $-11.5 \pm 4.2 \mu \mathrm{mol} \mathrm{kg}^{-1}$ over the whole cruise, not significantly different from the $-15.5 \mu \mathrm{mol} \mathrm{kg}^{-1}$ determined from my analyses.

\subsection{JH19940525 (134)}

The WDLSQ inversion of the crossover offsets suggested that an upward adjustment of $11.65 \mu \mathrm{mol} \mathrm{kg}{ }^{-1}$ was required to bring these data into consistency with the others. The comparison with the regression line derived using 316N20020530 (67) ALK data suggested - as expected - a somewhat smaller correction: $8.85 \mu \mathrm{mol} \mathrm{kg}{ }^{-1}$. However, the inversion result was confirmed by comparing with the regression line derived using deep data from non-offset cruises, $11.57 \mu \mathrm{mol} \mathrm{kg}^{-1}$.

The offset appeared constant throughout the cruise (not shown) and an upward adjustment of $11.6 \mu \mathrm{mol} \mathrm{kg}^{-1}$ is recommended for these data.

\subsection{JC19960720 (176)}

Both the inversion of the crossover results and the comparison with the 316N20020530 (67) ALK data, suggested that these data were low. The WDLSQ inversion suggested a correction of $15.38 \mu \mathrm{mol} \mathrm{kg}{ }^{-1}$, and this was in agreement with the estimate of $15.97 \mu \mathrm{mol} \mathrm{kg}^{-1}$, derived by comparing with the salinity-ALK regression line derived using deep data from cruises not subject to adjustment considerations. In addition, during this cruise CRMs were run, but had apparently not been used to correct the data. The raw data were available and an evaluation of these revealed a mean offset of $16.8 \mu \mathrm{mol} \mathrm{kg}{ }^{-1}$, which is - considering the uncertainties similar to the offset determined through the crossover and inversion, and linear regression analyses. Therefore an upward adjustment of $15.5 \mu \mathrm{mol} \mathrm{kg}{ }^{-1}$ is recommended for these data.

\section{Consistency test of final Nordic Seas ALK data}

In order to evaluate the consistency of the final Nordic Seas ALK data an automated crossover and inversion analysis was carried out on the data with recommendations implemented, using the cnaX scripts (Tanhua et al., 2009b). Although not part of CARINA, the TTO-NAS ALK data were included in order to obtain an impression of how comparable they are with the CARINA data. The TTO-NAS data that were used had been corrected according to Tanhua and Wallace (2005). The corrections determined by the WLSQ inversion of the crossover offsets are shown in blue in Fig. 3. The CARINA data appear consistent to within $\pm 3 \mu \mathrm{mol} \mathrm{kg}{ }^{-1}$. The TTONAS ALK data corrected according to Tanhua and Wallace (2005) are consistent with the CARINA data. The individual cruise tracks and ALK profiles of the Nordic Seas data included in the CARINA product are shown in Fig. 2. Note that the recommendations of this paper have been implemented in the merged data product, and that the data that were found to be questionable or bad have not been included. They have been retained in the individual cruise files, however. Both the merged data product and the individual cruise files are available at the CARINA home page at CDIAC (http://cdiac. ornl.gov/oceans/CARINA/Carina_inv.html). When the ALK data from a whole cruise were found to be questionable as reported here, they were not necessarily flagged as such in the individual cruise files, the flags in these are those assigned during the primary $\mathrm{QC}$. 
Acknowledgements. This effort would not have been possible without support from the Norwegian Research Council through A-CARB (188167) and the EU through IP CARBOOCEAN (511176). Additional support from the International Ocean Carbon Coordination Project (IOCCP) and the Hanse Institute for Advanced Study (HWK, Delmenhorst, Germany) has been very valuable. I would also like to express my gratitude to R. M. Key at Princeton University, T. Tanhua at Leibniz-Intitut für Meereswissenschaften and S. van Heuven at University of Groningen whose extensive efforts made the CARINA project possible. Finally I would like to thank the investigators who collected the data at sea, often during adverse conditions, and contributed their data to the CARINA project. The manuscript, which is contribution no. A262 of the Bjerknes Centre for Climate Research, benefitted from reviews by Melissa Chierici and an anonymous referee.

Edited by: T. Tanhua

\section{References}

Anderson, L. G., Jutterström, S., Kaltin, S., Jones, E. P., and Björk, G.: Variability in river runoff distribution in the Eurasian Basin of the Arctic Ocean, J. Geophys. Res., 109, C01016, doi:10.1029/2003JC001773, 2004.

Blindheim, J. and Østerhus, S.: The Nordic Seas, main oceanographic features, in: The Nordic Seas: an integrated perspective, edited by: Drange, H., Dokken, T., Furevik, T., Gerdes, R., and Berger, W., AGU Geohysical Monograph 158, AGU Washington DC, 2005

Chen, A, Jones, E. P., and Lin, K.: Wintertime total carbon dioxide measurements in the Norwegian and Greenland Seas, Deep-Sea Res., 37, 1455-1473, 1990.

Dickson, A. G., Sabine, C. L., and Christian, J. R. (Eds.): Guide to best practices for ocean $\mathrm{CO}_{2}$ measurements, PICES Special Publication 3, 191 pp., 2007.

Dickson, A. G.: An exact definition of total alkalinity and a procedure for the estimation of alkalinity and total inorganic carbon from titration data, Deep-Sea Res., 609-623, 1981.

Falck, E. and Olsen, A.: Nordic Seas dissolved oxygen data in CARINA, Earth Syst. Sci. Data Discuss., 2, 537-553, 2009, http://www.earth-syst-sci-data-discuss.net/2/537/2009/.

Gouretski, V. V. and Jancke, K.: Systematic errors as the cause for an apparent deep water property variability: global analysis of the WOCE and historical hydrographic data, Prog. Oceanog., 48, 337-402, 2001.

Haraldson, C., Anderson, L. G., Hassellöv, M., Hulth, S., and Olsson, K.: Rapid, high- precision potentiometric titration of alkalinity in ocean and sediment pore waters, Deep-Sea Res. Pt. I, 44, 2031-2044, 1997.

Hoppema, M., Velo, A., van Heuven, S., Tanhua, T., Key, R. M., Lin, X., Bakker, D. C. E., Perez, F. F., Ríos, A. F., Lo Monaco, C., Sabine, C. L., Álvarez, M., and Bellerby, R. G. J.: Consistency of cruise data of the CARINA database in the Atlantic sector of the Southern Ocean, Earth Syst. Sci. Data, 1, 63-75, 2009, http://www.earth-syst-sci-data.net/1/63/2009/.
Jeansson, E., Olsson, K. A., Tanhua, T., and Bullister, J. L.: Nordic Seas and Arctic Ocean CFC data in CARINA, Earth Syst. Sci. Data Discuss., 2, 493-536, 2009,

http://www.earth-syst-sci-data-discuss.net/2/493/2009/.

Johnson, G. C., Robbins, P. E., and Hufford, G. E.: Systematic adjustments of hydrographic sections for internal consistency, J. Atmos. Ocean. Tech., 18, 1234-1244, 2001.

Jutterström, S., Anderson, L. G., Bates, N. R., Bellerby, R., Johannessen, T., Jones, E. P., Key, R. M., Lin, X., Olsen, A., and Omar, A. M.: Arctic Ocean data in CARINA, Earth Syst. Sci. Data Discuss., 2, 281-308, 2009,

http://www.earth-syst-sci-data-discuss.net/2/281/2009/.

Key, R. M., Tanhua, T., Olsen, A., Hoppema, M., Jutterström, S., Schirnick, C., van Heuven, S., Kozyr, A., Lin, X., Velo, A., Wallace, D. W. R., and Mintrop, L.: The CARINA data synthesis project: introduction and overview, Earth Syst. Sci. Data Discuss., 2, 579-624, 2009, http://www.earth-syst-sci-data-discuss.net/2/579/2009/.

Lo Monaco, C., Álvarez, M., Key, R. M., Lin, X., Tanhua, T., Tilbrook, B., Bakker, D. C. E., van Heuven, S., Hoppema, M., Metzl, N., Ríos, A. F., Sabine, C. L., and Velo, A.: Assessing the internal consistency of the CARINA database in the Indian sector of the Southern Ocean, Earth Syst. Sci. Data Discuss., 2, 367-419, 2009,

http://www.earth-syst-sci-data-discuss.net/2/367/2009/.

Olafsson, J. and Olsen, A.: Nordic Seas nutrients data in CARINA, Earth Syst. Sci. Data Discuss., in preparation., 2009.

Olsen, A.: Nordic Seas total dissolved inorganic carbon data in CARINA, Earth Syst. Sci. Data, 1, 35-43, 2009, http://www.earth-syst-sci-data.net/1/35/2009/.

Olsen, A., Key, R. M., Jeansson, E., Falck, E., Olafsson, J., van Heuven, S., Skjelvan, I., Omar, A. M., Olsson, K. A., Anderson, L. G., Jutterström, S., Rey, F., Johannessen, T., Bellerby, R. G. J., Blindheim, J., Bullister, J. L., Pfeil, B., Lin, X., Kozyr, A., Schirnick, C., Tanhua, T., and Wallace, D. W. R.: Overview of the Nordic Seas CARINA data and salinity measurements, Earth Syst. Sci. Data, 1, 25-34, 2009,

http://www.earth-syst-sci-data.net/1/25/2009/.

Olsen, A., Omar, A. M., Bellerby, R. G. J., Johannessen, T., Ninnemann, U., Brown, K. R., Olsson, K. A., Olafsson, J., Nondal, G., Kivimäe, C., Kringstad, S., Neill, C., and Olafsdottir, S.: Magnitude and origin of the anthropogenic $\mathrm{CO}_{2}$ increase and ${ }^{13} \mathrm{C}$ Suess effect in the Nordic seas since 1981, Global Biogeochem. Cy., 20, GB3027, doi:10.1029/2005GB002669, 2006.

Sabine, C. L., Hoppema, M., Key, R. M., Tilbrook, B., van Heuven, S., Lo Monaco, C., Metzl, N., Ishii, M., Murata, A., and Musielewicz, S.: Assessing the internal consistency of the CARINA data base in the Pacific sector of the Southern Ocean, Earth Syst. Sci. Data Discuss., 2, 555-578, 2009, http://www.earth-syst-sci-data-discuss.net/2/555/2009/.

Seber, C. A. F.: Multivariate Observations, NJ, John Wiley \& Sons, Inc., 1984.

Tanhua, T., Steinfeldt, R., Key, R. M., Brown, P., Gruber, N., Wanninkhof, R., Perez, F., Körtzinger, A., Velo, A., Schuster, U., van Heuven, S., Bullister, J. L., Stendardo, I., Hoppema, M., Olsen, A., Kozyr, A., Pierrot, D., Schirnick, C., and Wallace, D. W. R.: Atlantic Ocean CARINA data: overview and salinity adjustments, Earth Syst. Sci. Data Discuss., 2, 241-280, 2009a, http://www.earth-syst-sci-data-discuss.net/2/241/2009/. 
Tanhua, T., van Heuven, S., Key, R. M., Velo, A., Olsen, A., and Schirnick, C.: Quality control procedures and methods of the CARINA database, Earth Syst. Sci. Data Discuss., 2, 205-240, 2009b,

http://www.earth-syst-sci-data-discuss.net/2/205/2009/.

Tanhua, T. and Wallace, D. W. R.: Consistency of TTO-NAS inorganic carbon data with modern measurements, Geophys. Res. Lett., 32, L14618, doi:10.1029/2005GL023248, 2005.

Velo, A., Pérez, F. F., Lin, X., Key, R. M., Tanhua, T., de la Paz, M., van Heuven, S., Jutterström, S., and Ríos, A. F.: CARINA data synthesis project: $\mathrm{pH}$ data scale unification and cruise adjustments, Earth Syst. Sci. Data Discuss., 2, 421-475, 2009a, http://www.earth-syst-sci-data-discuss.net/2/421/2009/.
Velo, A., Perez, F. F., Brown, P., Tanhua, T., Schuster, U., and Key, R. M.: CARINA alkalinity data in the Atlantic Ocean, Earth Syst. Sci. Data, 1, 45-61, 2009b, http://www.earth-syst-sci-data.net/1/45/2009/.

Yager, P. L., Wallace, D. W. R., Johnson, K. M., Smith Jr., W. O., Minnett, P. J., and Deming, J. W.: The Northeast Water Polynya as an atmospheric $\mathrm{CO}_{2}$ sink: A seasonal rectification hypothesis, J. Geophys. Res., 100, 4389-4398, 1995. 